\title{
Improved Mäule color reaction provides more detailed information on syringyl lignin distribution in hardwood
}

\author{
Daichi Yamashita $^{1} \cdot$ Satoshi Kimura $^{2,3} \cdot$ Masahisa Wada $^{1,3} \cdot$ Keiji Takabe $^{1}$
}

Received: 14 August 2015/Accepted: 21 December 2015/Published online: 8 February 2016

(C) The Japan Wood Research Society 2016

\begin{abstract}
The traditional Mäule color reaction was improved by use of tris(hydroxymethyl) aminomethanehydrochloride acid (Tris- $\mathrm{HCl}$ ) buffer coupled with a fluorescence microscope. The purple-red color of Mäule-treated hardwood was more stable with the novel treatment than with traditional treatment. In addition, Mäule-treated wood samples had a characteristic fluorescence when excited with blue (460-495 nm) light. Examination of white birch (Betula platyphylla) showed that syringyl-rich and guaiacyl-rich cell walls emitted red and yellow fluorescence, respectively. Measuring the fluorescence spectra of hardwood and softwood powders after treatment with the new Mäule reagents showed that hardwood powder containing syringyl lignin emitted a red fluorescence, whereas softwood powder containing guaiacyl lignin emitted a green fluorescence when excited with blue light. In conclusion, this improved technique has many advantages compared with the traditional Mäule color test.
\end{abstract}

Part of this report was presented at the IAWPS International Symposium on Wood Science and Technology 2015, Tokyo, March 2015.

Keiji Takabe

kjtakabe@kais.kyoto-u.ac.jp

1 Division of Forest and Biomaterials Science, Graduate School of Agriculture, Kyoto University, Kyoto 606-8502, Japan

2 Laboratory of Biomass Morphogenesis and Information, Research Institute for Sustainable Humanosphere, Kyoto University, Kyoto 611-0011, Japan

3 Department of Plant and Environmental New Resources, College of Life Sciences, Kyung Hee University, 1, Seocheon-dong, Giheung-ku, Yongin-si, Gyeonggi-do 446-701, Korea
Keywords Mäule color test · Lignin · Fluorescence · Color reaction

\section{Introduction}

The cell walls of wood consist of three main components: cellulose, hemicellulose, and lignin. Lignin accounts for $20-35 \%$ of the dry weight of cell walls, and provides wood with hardness, hydrophobicity, and resistance to biochemical invasion. Lignin is a hetero-polymer and contains three types of unit, called as syringyl, guaiacyl, and $p$-hydroxyphenyl units. The amount of lignin and ratio of these units in cell walls result from cell differentiation and affect the chemical or physical properties of the cell wall. Therefore, the ability to predict lignin distribution and the unit ratio in the cell walls of woody plants is important.

Because microscopic analysis provides useful information on the existence and distribution of cell wall components, many methods for microscopic examination have been developed to detect lignin. Lignin typically absorbs ultraviolet (UV) light; thus, a UV microscope is a powerful tool for its detection [1]. Some chemical reagents can provide information on the existence of lignin. For example, potassium permanganate $\left(\mathrm{KMnO}_{4}\right)$ is often used to investigate cell wall lignification by transmission electron microscopy [2]. Staining with acriflavine [3] or safranine [4] can permit the detection of lignin because fluorescent coloration can indicate the concentration ratio of lignin and cellulose. However, these staining methods cannot be used to identify specific structure of lignin. Other methods have been used to detect specific structures in lignin. The Wiesner reaction (phloroglucinol- $\mathrm{HCl}$ reaction) can be used to detect $O$-4-linked coniferyl and sinapyl aldehydes in lignin [5]. The Mäule color test, which is performed by 
sequential treatment with potassium permanganate, hydrochloride, and aqueous ammonia, is one of the most useful methods for detecting lignin. This method produces purple-red emissions with hardwood samples, and has been widely used to distinguish hardwoods from softwoods. Meshituka and Nakano [6-8] reported that the purple-red color is due to 3-methoxy-o-quinone structures generated from syringyl lignin. Iiyama and Pant [9] suggested that $\beta$ ether cleavage under permanganate oxidation can liberate the syringyl groups and generate the Mäule color that is emitted. These reports show that the Mäule treatment is effective for detecting syringyl lignin. However, the Mäule reaction has several flaws including rapid color fading, leaching of colored lignin into aqueous ammonia, and swelling or breaking of tissue samples. Thus, although it is a useful technique, many improvements are needed.

In this study, we compared the traditional method, which uses aqueous ammonia, with this new Mäule technique, which uses tris(hydroxymethyl)aminomethane-hydrochloride acid (Tris-HCl) buffer, to develop color and examine the fluorescence of wood samples excited with blue light.

\section{Materials and methods}

\section{Samples}

The specimens used in this study were sapwoods of white birch (Betula platyphylla), Japanese cedar (Cryptomeria japonica), and Japanese oak tree (Quercus crispula).

The white birch was harvested at the Tohoku Research Center of Forestry and Forest Products Research Institute. Twenty $\mu \mathrm{m}$ thick transverse and radial sections of the white birch were prepared with a sliding microtome. In addition, the birch sample was embedded in methacrylate resin and the $1 \mu \mathrm{m}$ thick transverse section was cut for an UV microscope. Embedding in the methacrylate resin was carried out as followed. The small pieces of samples were dehydrated with ethanol-graded series. The dehydrated samples were substituted in absolute acetone, then in methacrylate resin (n-butyl methacrylate: methyl methacrylate $=7: 3$, containing $1.5 \%$ of benzyl peroxide as initiator), and polymerized at $50{ }^{\circ} \mathrm{C}$ for overnight in gelatin capsule. After preparing sections, the resin was dissolved with acetone. For measuring fluorescence spectra, wooden powder was obtained from birch using Willey mill (1024 J-A, Yoshida Seisakusho Co., Ltd, Japan). The powder was sieved into $\sim 177 \mu \mathrm{m}$ in diameter.

The oak trees were harvested at the Field Science Education and Research Center of Kyoto University in the Ashiu Forest Research Station on July 25, 2014, and were used for the observation of cambium and differentiating xylem. Specimens were obtained at breast height of the tree, and fixed with $2.5 \%$ paraformaldehyde containing $50 \mathrm{mM} \mathrm{KPB}$ and $0.4 \mathrm{M}$ sucrose. After fixation, the samples were washed in distilled water and stored in $30 \%$ ethanol until subsequent analysis. Forty $\mu \mathrm{m}$ thick transverse sections of Japanese oak tree were obtained using a freezing microtome. In addition, thin transverse sections were obtained from the sample embedded in LR White resin. The sections were prepared as serial sections that thickness was 5 and $3 \mu \mathrm{m}$ alternately. Embedding in LR White resin was conducted by washing the sample for $30 \mathrm{~min}$ with $50 \mathrm{mM}$ potassium phosphate buffer and four times with $0.4 \mathrm{M}$ sucrose. Next, specimens were dehydrated with an ethanol-graded series. The dehydrated specimens were substituted in 25,50 , and $75 \%$ LR White resin for $24 \mathrm{~h}$ for each step, and then embedded in $100 \%$ LR White resin.

The Japanese cedar was harvested at Kyoto, Japan. Wooden powder obtained as the same way for birch was used for measuring fluorescence spectra of Mäule-treated softwood.

\section{Mäule treatment}

Traditional Mäule samples were treated with $1 \% \mathrm{KMnO}_{4}$ aqueous solution for $5 \mathrm{~min}$, washed with distilled water three times, treated with $1 \mathrm{~N}$ hydrochloric acid for $30 \mathrm{~min}$, and then washed with distilled water. To generate a color reaction, $28 \%$ aqueous ammonia was added to the sections mounted on glass slides and covered with cover slips. For samples treated using the new Mäule method, Tris- $\mathrm{HCl}$

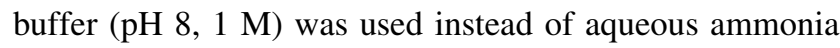
to generate color.

\section{Microscopic observation}

Twenty $\mu \mathrm{m}$ thick Mäule-treated birch sections were photographed under a light or fluorescence microscope (LX71; Olympus, Japan). Fluorescence was excited by blue light $(460-495 \mathrm{~nm})$ and observed at a wavelength $>510 \mathrm{~nm}$ using a filter cube (U-MWIB filter cube; Olympus, Japan). The observation was done within 15 min following color development. To examine the speed of color fading, birch samples were photographed 0-10, 30-40, and 60-70 min after color development. These experiments were repeated at least three times. The sections obtained from other part in the same log were also examined for confirmation. Then, $1 \mu \mathrm{m}$ thick transverse sections of resin-embedded birch were observed under a UV microscope (UMSP-80; Carl Zeiss, Germany) with absorbance at $280 \mathrm{~nm}$ for observing lignin distribution in vessels.

A $40 \mu \mathrm{m}$ thick Japanese oak tree section was also treated with new Mäule reagents and photographed under a light and a fluorescence microscope. Three sections were 
treated at same time and photographed within 15 min after treatment finished. These experiments were repeated at least 3 times in different days. For detecting the fiber that secondary cell wall formation started, the section that had $3 \mu \mathrm{m}$ thickness following next $5 \mu \mathrm{m}$ thickness section was photographed under a polarizing microscope (BHA-751P, Olympus, Japan). Three pairs of serial sections obtained from three different blocks were examined.

\section{Measurement of visible light absorption spectra using new Mäule regents}

In total, $20 \mathrm{mg}$ of $20 \mu \mathrm{m}$ thick transverse sections of birch was treated with traditional Mäule or new Mäule reagents in $1 \mathrm{~mL}$ sample tubes. The samples were centrifuged $(20,000 \times g, 1 \mathrm{~min})$ between each step. After developing color, visible light absorption spectra of supernatant were measured with a UV-visible light spectrometer (UV-1600; Shimadzu, Japan).

\section{Measurement of fluorescence spectra after Mäule reaction}

After wood powders of birch or cedar treated with traditional or new Mäule reagents were centrifuged to obtain precipitates, moist samples were set on a frost glass sample holder, which is usually used in X-ray diffractometry. Fluorescence spectra were measured after excitation at
Fig. 1 Transverse sections (20 $\mu \mathrm{m}$ thick) of birch treated with traditional $(\mathbf{a}-\mathbf{f})$ and new Mäule reagents $(\mathbf{g}-\mathbf{l})$ at $0-10(\mathbf{a}$, $\mathbf{d}, \mathbf{g}, \mathbf{j}), 30-40(\mathbf{b}, \mathbf{e}, \mathbf{h}, \mathbf{k})$, and 60-70 (c, f, i, l) min following treatment. The sections were color photographed under white light $(\mathbf{a}-\mathbf{c}, \mathbf{g}-\mathbf{i})$ or excited with blue light $(\mathbf{d}-\mathbf{f}, \mathbf{j}-\mathbf{l})$
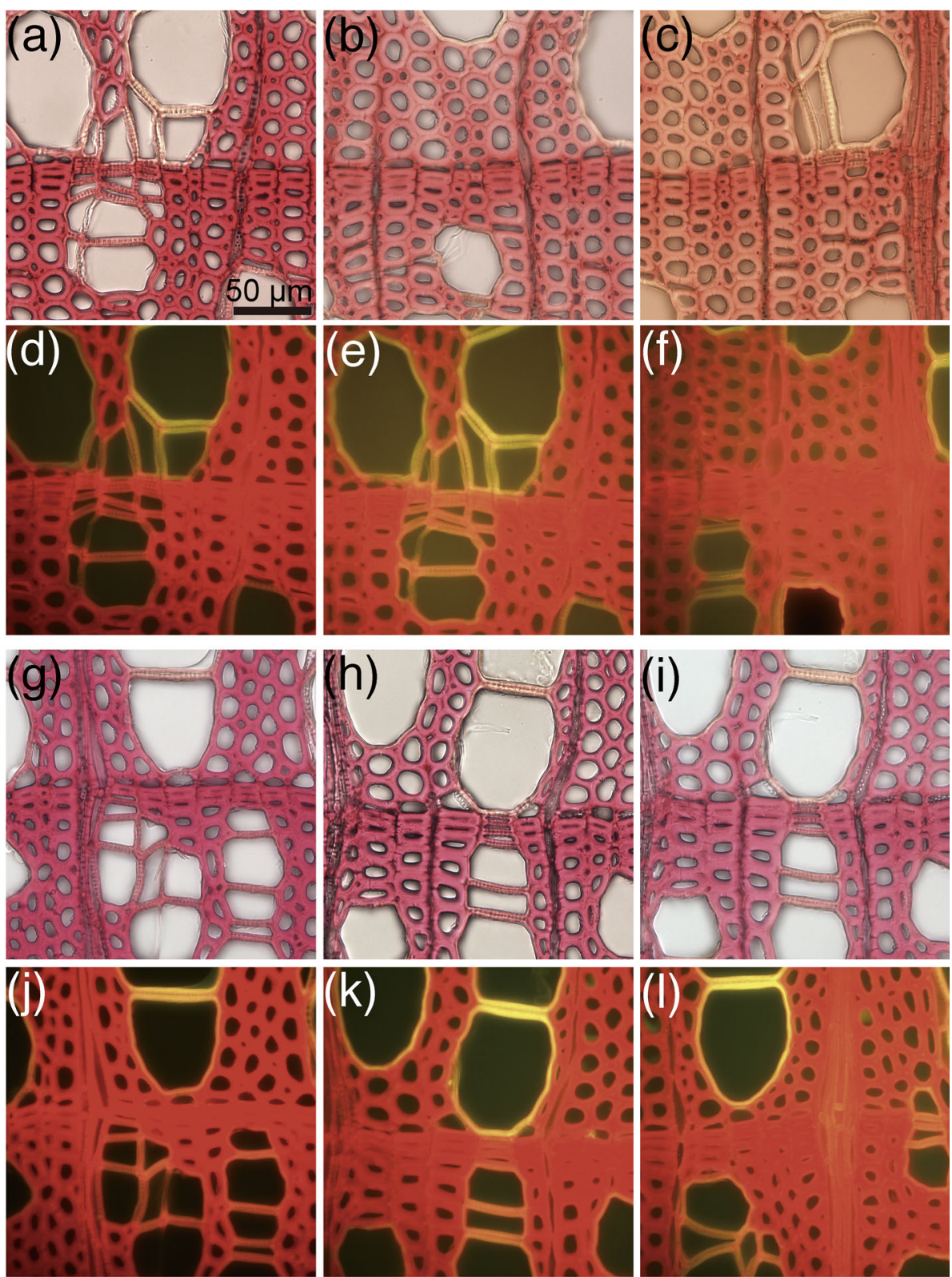
$480 \mathrm{~nm}$ using a fluorescence spectrometer (RF-5300PC; Shimadzu, Japan).

\section{Results and discussion}

\section{Effects of changing reagents and observation methods}

The transverse sections of white birch sapwood treated using the traditional or new Mäule treatment showed similar purple-red color under white light (Fig. 1). Regarding color fading, we found that the purple-red color developed with traditional Mäule reagents faded within 30-60 min (Fig. 1b) and that the reagents were red after $60 \mathrm{~min}$, whereas purple-red colors developed with new Mäule reagents did not fade, even after $60 \mathrm{~min}$ and the reagents were not colored (Fig. 1h, i). The change in reagents resulted in resistance to fading over time. Figure 2 shows the visible light absorption of colored Mäule reagents obtained as supernatants from $20 \mathrm{mg}$ of birch transverse sections. The purple-red color of the Mäule reaction has the maximum absorption spectrum at $520 \mathrm{~nm}$. The absorption of the new Mäule reagent was less than half of that found for the traditional Mäule reagent at $520 \mathrm{~nm}$. These results show that the new reagent extracted less visible-colored lignin from the cell wall.

When Mäule-treated white birch was observed under blue light (460-495 nm), cell walls showed characteristic fluorescence (Fig. 1d-f, j-1). The cell walls of wood fibers, ray, and axial parenchyma emitted a red fluorescence, whereas the vessel cell wall emitted a yellow to red fluorescence. Figure 3 shows the photograph of the area around the annual ring boundary in white birch section after Mäule

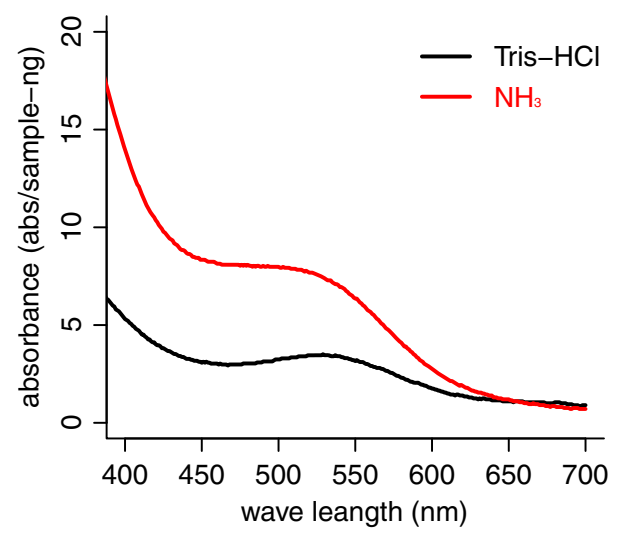

Fig. 2 The visible light absorbance of colored reagents after the traditional Mäule treatment (red line aqueous ammonia) and the new Mäule treatment (black line Tris- $\mathrm{HCl}$ buffer); $520 \mathrm{~nm}$ is the maximum adsorption of lignin after Mäule treatment
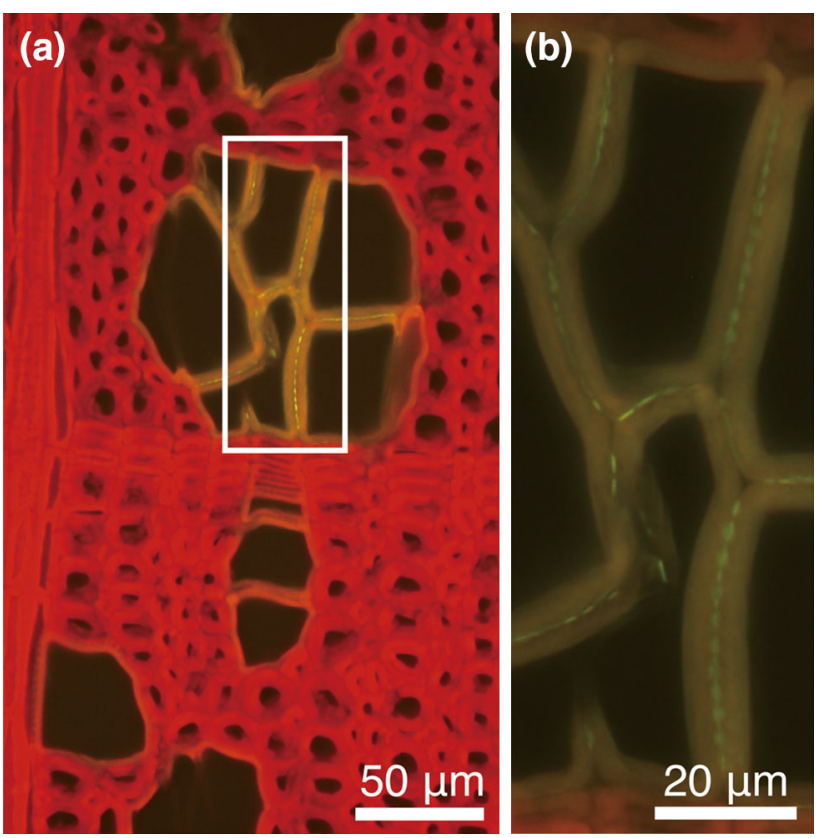

Fig. 3 Transverse section of birch treated with the new Mäule reagents and photographed with blue light excitation (b) is enlargement of boxed area in a

treatment. The fluorescence colors in the vessel cell walls were yellow in earlywood and became more reddish in latewood. Takabe et al. [10] reported that the proportion of guaiacyl units in vessel secondary walls is high for earlywood and lower in latewood. Therefore, the difference in colors for vessel cell walls indicates that the ratio of the syringyl to guaiacyl (S/G ratio) is lower for earlywood and higher for latewood. In addition, the pit membranes in the vessel cell walls showed a green fluorescence color, which was different from the yellow fluorescence of the vessel secondary cell walls. This suggests that $\mathrm{S} / \mathrm{G}$ ratio of lignin in pit membranes differs from that found in the vessel secondary wall. When the thin section of white birch was observed under a UV microscope, the pit membrane had higher absorbance than the other cell walls (Fig. 4), which suggests that the pit membrane has a larger amount of lignin, or a higher ratio of guaiacyl lignin. Thus, the green color in the pit membrane of this birch sample might be due to a very high proportion of guaiacyl lignin. This method provided other valuable information. Tylosis had a green fluorescence in some vessels, although cell walls of the vessel emitted a red fluorescence in the thin innermost layer (Fig. 5).

The radial section of birch following Mäule treatment is shown in Fig. 6. When the section was observed with blue light excitation, the inter-vessel cell walls showed a heterogeneous fluorescence (Fig. 6b), which was not clarified by light microscopy (Fig. 6a). The cell walls of 


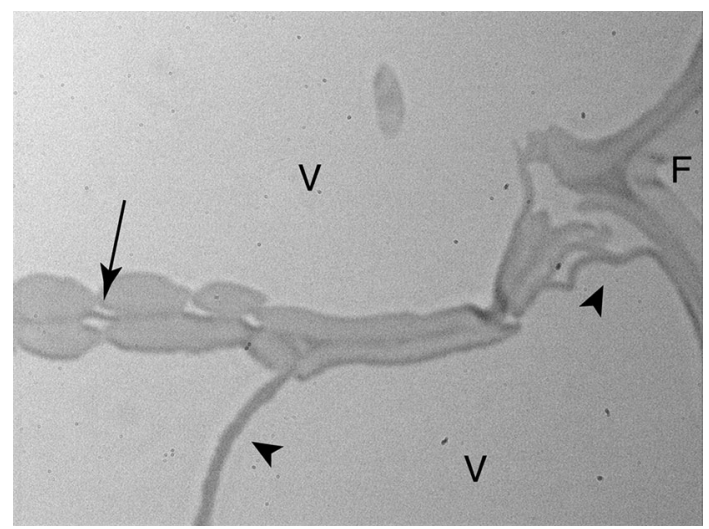

Fig. 4 Ultraviolet (UV) microscopic photograph of the birch vessel wall. Pit membrane (arrow) and tylosis cell walls (arrowhead) had higher UV adsorptions than the vessel cell walls. $F$ fiber, $V$ vessel

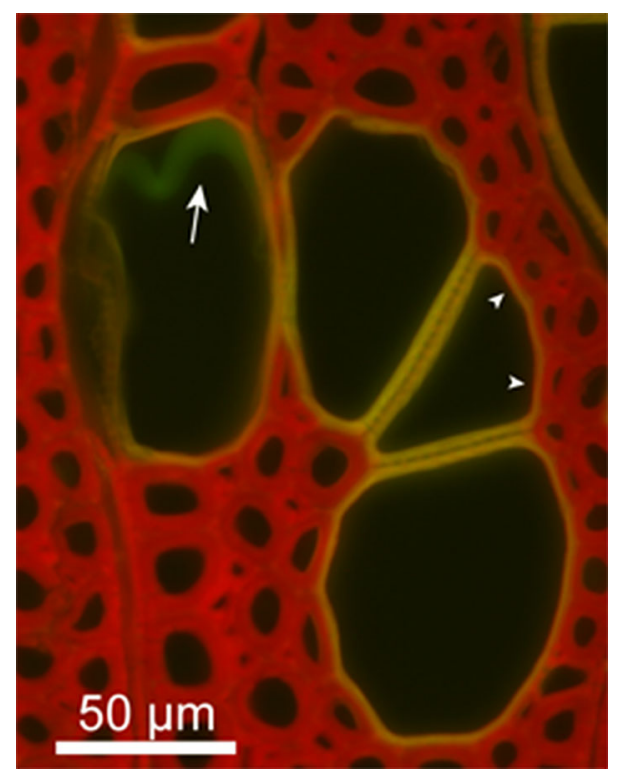

Fig. 5 Vessel walls of birch treated with new Mäule reagents and photographed with blue light excitation. Tylosis showed a green fluorescence (arrow), although the innermost layer of the vessel cell wall showed a red fluorescence (arrowhead)

vessels mainly had a yellow fluorescence, whereas intervessel cell walls emitted a green fluorescence particularly around the vessel perforation. The pit membrane demonstrated a green fluorescence (Fig. 6c, arrow) that was similar to that shown in Fig. 3. This suggests that vessel cell walls have a guaiacyl-rich area, and their lignification can be heterogeneous.

\section{Fluorescence spectra of Mäule-treated wood powders}

For the purpose of defining the wavelength of fluorescence color in Mäule-treated samples, fluorescence spectra were
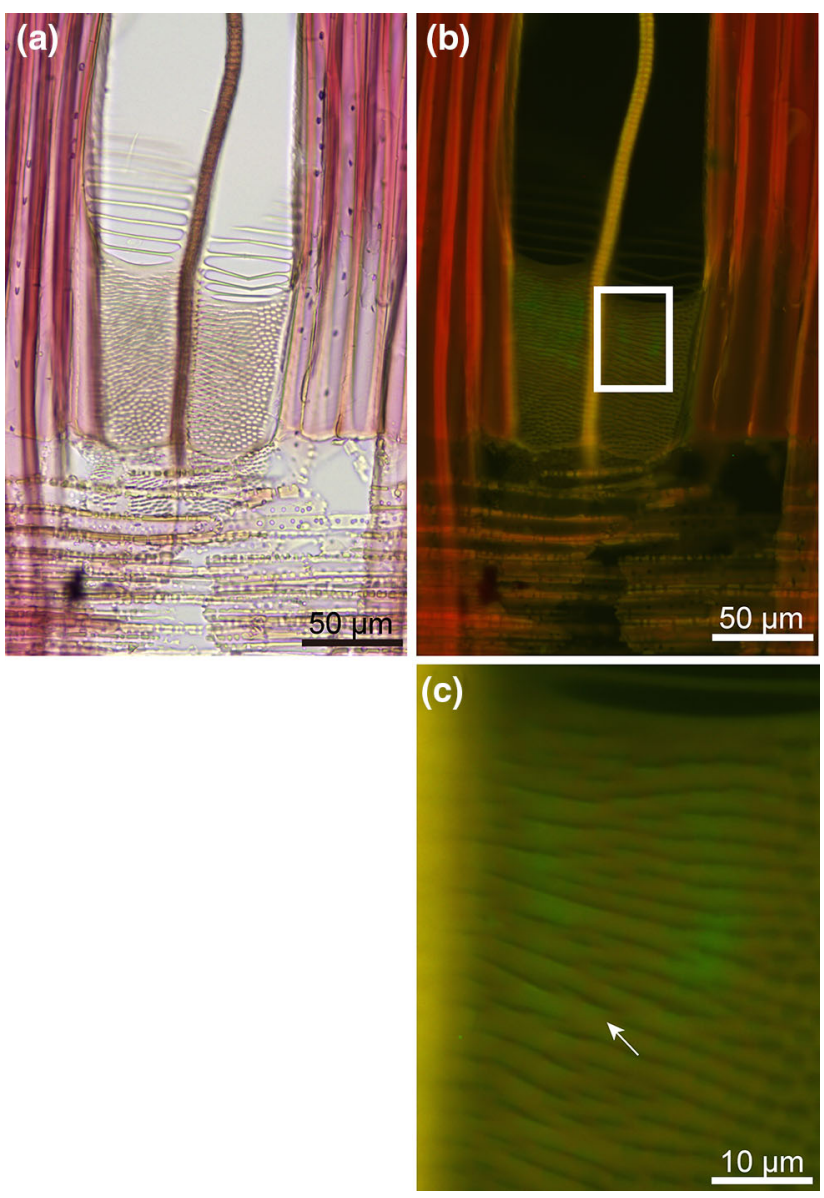

Fig. 6 The radial section of birch treated with the new Mäule reagents and photographed under white light (a) and excited with blue light (b). $\mathbf{c}$ This indicates enlargement of boxed area in $\mathbf{b}$. The intervessel cell wall had an area that showed green fluorescence (arrow)

measured. The fluorescence spectra of birch and cedar powders are shown in Fig. 7. Both wood powders treated with aqueous ammonium showed a green fluorescence, which peaked at $540 \mathrm{~nm}$ when the specimens were excited by blue light $(480 \mathrm{~nm})$. After traditional or new Mäule treatment, birch wood samples showed a red fluorescence that peaked at 635 or $645 \mathrm{~nm}$, respectively. These small differences in maximum peak wavelength might have occurred due to the difference in $\mathrm{pH}$ of the two reagents. The yellow fluorescence was not observed in spectra obtained from wood powders, whereas the microscopic observation showed a yellow color in vessel cell walls. It should be noted that this spectrum was an average of spectra from various kinds of cell walls, and vessel cell walls containing guaiacyl lignin were only a small part of the sample. On the other hand, the spectra of Japanese cedar, in which lignin was mostly composed of guaiacyl units, had a maximum peak at $550 \mathrm{~nm}$ after Mäule treatment, whereas the untreated sample peaked at $540 \mathrm{~nm}$ due to autofluorescence. The fluorescence at 540 and $550 \mathrm{~nm}$ is 


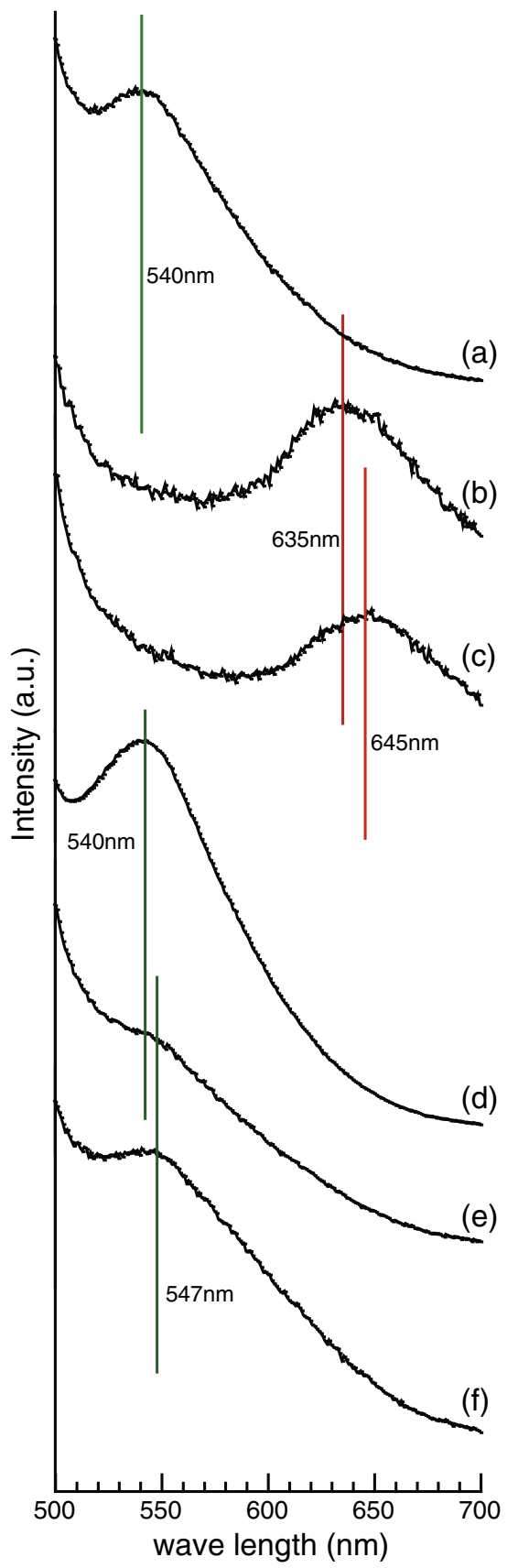

Fig. 7 The fluorescence spectra of birch (a-c) and Japanese cedar (d-f) after being washed with aqueous ammonia (a and d), after the traditional Mäule reaction (b and e), and after Tris-Mäule treatment (c and $\mathbf{f}$ )

yellow-green. Hence, syringyl lignin shows a red fluorescence and guaiacyl lignin shows a yellow-green fluorescence. The yellow fluorescence in the vessel cell walls of birch wood might be due to a mixture of red and green fluorescence.

\section{Application to samples that are difficult to analyze}

The new Mäule methods improved the observation of lignin, and emitted colors reflecting the difference of lignin. Figure 8 shows light and fluorescence microscopic photographs of transverse sections ( $40 \mu \mathrm{m}$ thick) of Japanese oak, including the cambial zone after new Mäule treatment. The guaiacyl-rich cell walls have a brownish color after standard Mäule treatment. With this new treatment, the cambial zone and cell-enlarging zone showed a brownish color when observed under white light. Therefore, information on the distribution of guaiacyl lignin could not be obtained from this picture (Fig. 8a). However, when the same section was observed under a fluorescence microscope, the cell walls in secondary wall formation showed a yellow-green florescence and became reddish following cell wall formation (Fig. 8b). Thus, this new method can detect the accumulation of syringyl lignin after the accumulation of guaiacyl lignin. Therefore, the new method coupled with fluorescence microscopy can be used to confirm the existence of lignin, similar to that found using UV adsorption. However, our new method has useful advantages such as simultaneously being able to visually assess syringyl and guaiacyl lignin distributions, while distinguishing false brown color emissions that result from permanganate oxidation.

This method can also be used to observe lignin distribution in semi-thin, resin-embedded sections. The semithin ( $5 \mu \mathrm{m}$ thick) transverse section obtained from Japanese oak embedded in LR White resin was treated with new Mäule reagents and emitted a weak red fluorescence when observed under a fluorescence microscope (Fig. 9). It was difficult to observe the lignin distribution under white light because the cell walls were pale pink (data not shown). Resin-embedded semi-thin sections enabled us to observe the cell wall formation under a polarizing microscope. Because the outer layer of the secondary wall $\left(S_{1}\right)$ has birefringence, the start of $S_{1}$ formation can be detected under a polarizing microscope, because the microfibril orientation is parallel to the transverse plane. The fibers in the $S_{1}$-forming stage did not show a red or yellow-green fluorescence. As secondary wall formation proceeded, the cell wall began to emit a green fluorescence in 6-8 cells beyond the $S_{1}$ forming cell and became a reddish fluorescence after 9-10 cells. This indicates that lignification in secondary walls starts with an accumulation of guaiacyl lignin lagging behind $S_{1}$ formation, followed by accumulation of syringyl lignin in a few cells following those that begin guaiacyl lignin accumulation. 
Fig. 8 Transverse sections ( $40 \mu \mathrm{m}$ thick) of Japanese oak including the cambium zone after being treated using the new Mäule method
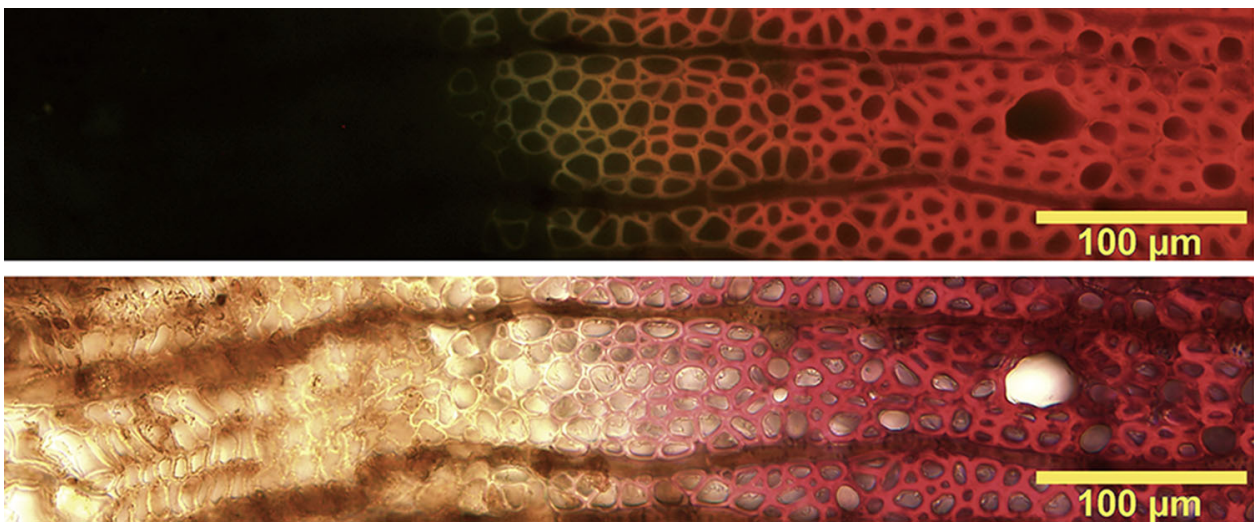

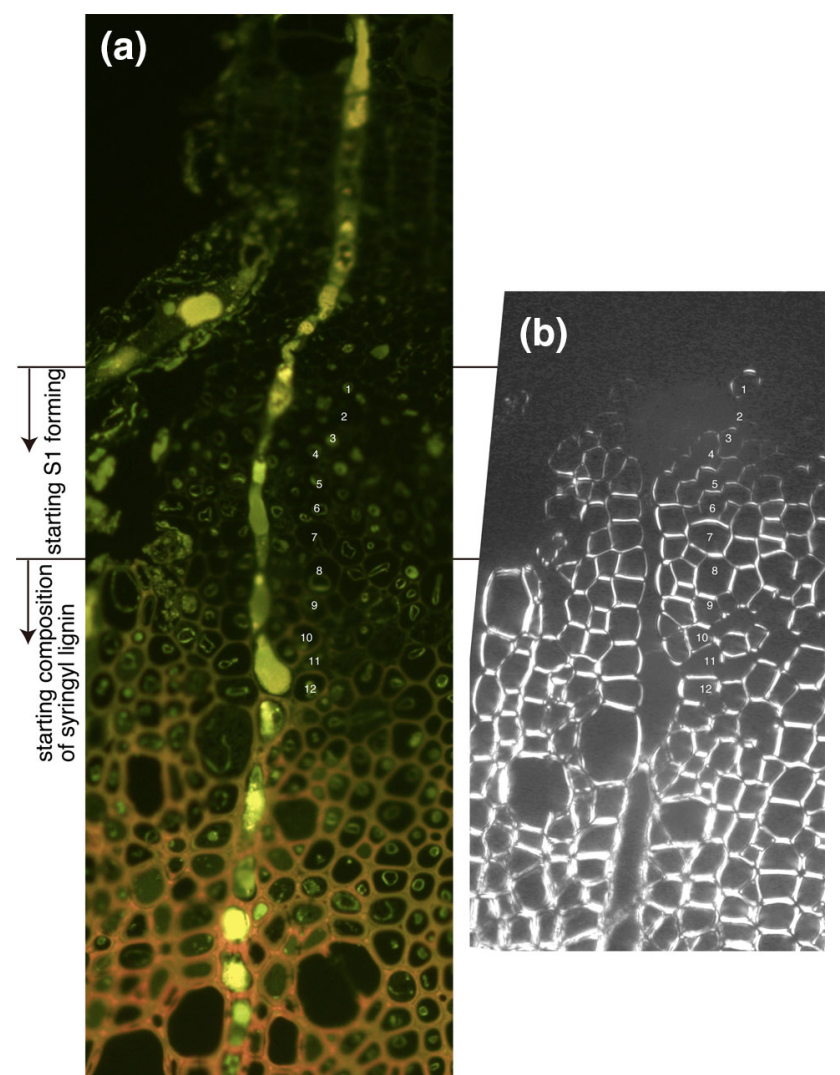

Fig. 9 Semi-thin transverse sections $(5 \mu \mathrm{m}$ thick) of Japanese oak embedded in LR White resin, treated with the new Mäule method, and photographed with a fluorescence microscope (a) or observed with a polarized microscope $(\mathbf{b}, 3 \mu \mathrm{m})$

\section{Conclusions}

Using a Tris- $\mathrm{HCl}$ buffer instead of ammonia in the Mäule reaction results in similar color development as that found using the traditional method. In addition, this new method is resistant to color fading with time. Moreover, evaluation after blue light excitation (around $480 \mathrm{~nm}$ ) improves the observation of lignification and lignin distribution, because syringyl lignin emits red fluorescence (around $640 \mathrm{~nm}$ ) and guaiacyl lignin fluoresces yellow-green $(\sim 550 \mathrm{~nm})$. Our method provides visual information on the heterogeneous distribution of lignin in hardwoods. The analysis of woody anatomy would be improved using this novel Mäule method.

Acknowledgments This work was supported by the Grant-in-Aid for JSPS Fellows (26-11122).

\section{References}

1. Scott JAN, Procter AR, Fergus BJ, Goring DAI (1969) The application of ultraviolet microscopy to the distribution of lignin in wood. Description and validity of the technique. Wood Sci Technol 3:73-92

2. Bland DE, Foster RC, Logan AF (1971) Mechanism of permanganate and osmium tetroxide fixation and distribution of lignin in cell wall of Pinusradiata. Holzforschung 25(5):137-143

3. Donaldson L, Hague J, Snell R (2001) Lignin distribution in coppice poplar, linseed and wheat straw. Holzforschung 55(4):379-385

4. Bond J, Donaldson L, Hill S, Hitchcock K (2007) Safranine fluorescent staining of wood cell walls. Biotech Histochem 83(3-4):161-171

5. Pomar F, Merino F, Ros Barceló A (2002) O-4-Linked coniferyl and sinapyl aldehydes in lignifying cell walls are the main targets of the Wiesner (phloroglucinol-HCl) reaction. Protoplasma 220:17-28

6. Meshitsuka G, Nakano J (1977) Studies on the mechanism of lignin color reaction XI. Mäule color reaction (7). Mokuzai Gakkaishi 23:232-236

7. Meshitsuka G, Nakano J (1978) Studies on the mechanism of lignin color reaction XII. Mäule color reaction (8). Mokuzai Gakkaishi 24:563-568

8. Meshitsuka G, Nakano J (1979) Studies on the mechanism of lignin color reaction XIII. Mäule color reaction (9). Mokuzai Gakkaishi 25:588-594

9. Iiyama K, Pant R (1988) The mechanism of Mäule colour reaction Introduction of methylated syringyl nuclei into softwood lignin. Wood Sci Technol 22:167-175

10. Takabe K, Miyauchi S, Tsunoda R, Fukazawa K (1992) Distribution of guaiacyl and syringyl lignins in Japanese beech (Fagus crenata): variation within an annual ring. IAWA Bull 13:105-112 